\title{
ADUBAÇÃO NITROGENADA E USO DE REGULADOR DE CRESCIMENTO NA PRODUÇÃO DE TRIGO DE SEQUEIRO
}

Claudio Hideo Martins da Costa, Jordana Rafaela Guimarães Vilela, Ana Laura Silva de Sousa, Rogério Borges de Oliveira Paz, Bárbara Fátima Silva Moura

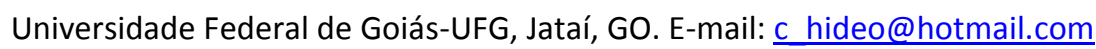

\section{RESUMO}

A adubação nitrogenada é uma importante prática de manejo em gramíneas e bastante complexa, em função dos diversos fatores que influenciam, como condições climáticas, sistemas de cultivo, doses e fontes disponíveis. Objetivou-se com o trabalho, avaliar diferentes doses de nitrogênio em cobertura e o efeito do regulador de crescimento etil-trinexapac no trigo (Triticum aestivum L.). 0 experimento foi em blocos casualizados em esquema fatorial $5 \times 2$, com 4 repetições. Os tratamentos foram compostos por cinco doses de nitrogênio aplicado em cobertura $\left(0,20,40,80\right.$ e $160 \mathrm{~kg} \mathrm{ha}^{-1}$ de $\left.\mathrm{N}\right)$ e duas doses do etil-trinexapac $(0$ e $100 \mathrm{~g} \mathrm{ha}^{-1}$ do ingrediente ativo) na cultura do trigo. Foram avaliadas: Massa de matéria seca, altura de planta, altura da folha bandeira, altura de inserção de espiga, distância fonte e dreno, comprimento de espiga, número de espigas por metro quadrado, número de espiguetas por espiga, fertilidade das espiguetas, número de grãos por espiga, número de grãos por espigueta, massa de mil grãos, produtividade de grãos), peso hectolitro e proteína dos grãos. O regulador de crescimento altera os componentes morfológicos do trigo, porém não altera os componentes produtivos e a produtividade de grãos, não justificando seu uso nas condições em que ocorreu o estudo. A adubação nitrogenada não altera os componentes morfológicos das plantas do trigo, mas aumenta o número de espigas por $\mathrm{m}^{2}$ (afilhos) até dose de $52 \mathrm{~kg} \mathrm{ha}^{-1}$ de $\mathrm{N}$, refletindo no aumento da produtividade até a dose de $59 \mathrm{~kg} \mathrm{ha}^{-1}$.

Palavras-chave: Triticum aestivum; nitrogênio; etil-trinexapac.

\section{NITROGEN FERTILIZATION AND GROWTH REGULATOR USE IN UPLAND WHEAT PRODUCTION}

\begin{abstract}
Nitrogen fertilization is an important management practice in grasses and quite complex, due to the different factors that influence such as climatic conditions, cropping systems, rates and available sources. The objective of this work was to evaluate the different rates of side dressing nitrogen and the effect of the trinexapac-ethyl on wheat (Triticum aestivum L.). The experiment was a randomized block design in a $5 \times 2$ factorial scheme, with 4 replicates. The treatments were composed of five nitrogen rates applied in side dressing $\left(0,20,40,80\right.$ and $160 \mathrm{~kg} \mathrm{ha}^{-1}$ of $\mathrm{N}$ ) and two rates of etil-trinexapac (0 e $100 \mathrm{~g} \mathrm{ha}^{-1}$ do active ingredient) in the wheat crop. The following variables were evaluated: shoot dry matter, plant height, flag leaf height, ear insertion height, distance of source and drain, ear length, number of ears per square meter, number of spikelets per ear, fertility of spikelets, number of grains per ear, number of grains per spikelet, mass of one thousand grains, grain yield), hectoliter weight, and grain protein. The growth regulator changes the morphological components of wheat, but does not alter the productive components and yield of grains, not justifying their use under the conditions under which the study took place. Nitrogen fertilization does not alter the morphological components of wheat plants, but increases the number of ears per $\mathrm{m}^{2}$ up to a rate of $52 \mathrm{~kg} \mathrm{ha}^{-1}$ of $\mathrm{N}$, reflecting the increase in productivity up to the rate of $59 \mathrm{~kg} \mathrm{ha}^{-1}$.
\end{abstract} Keywords: Triticum aestivu; nitrogen; etil-trinexapac.

\section{INTRODUÇÃO}

A produção de grãos no Brasil tem crescido continuamente nos últimos anos, e está concentrada basicamente em dois produtos: soja e milho. Juntos, responderam na temporada $2015 / 16$ por $86,7 \%$ de toda a oferta nacional de 
grãos. Esse quadro faz com que o país necessite encarar, com a relevância que o caso requer, uma política de estímulos para os demais produtos essenciais à dieta do brasileiro. É o caso, por exemplo, dos produtos: arroz, feijão e trigo, para citar os mais importantes, cujas ofertas instáveis repercutem de forma danosa na gestão de vários agentes do mercado, particularmente no caso do trigo, com suas históricas intervenções através das importações, para regularizar o abastecimento interno (CONAB, 2017).

A estimativa de produção de trigo no Brasil é de 5,46 milhões de toneladas, enquanto a demanda interna é de 10,9 milhões, resultando em um déficit de 5,44 milhões de toneladas, que são supridas com importações - dados da Safra de 2016/2017 (CONAB, 2017). Para diminuir a dependência de outros países, além do direcionamento de políticas adequadas ao setor, investimentos em tecnologia de produção ainda são necessários.

Com o objetivo de aumentar a produção interna, o governo já vem procurando estimular o plantio do cereal na Região Centro-Oeste, numa perspectiva de que o plantio nas áreas centrais do país poderia incrementar a receita bruta das unidades de produção, além de gerar uma oferta que venha a suprir a demanda interna. De acordo com Teixeira Filho et al. (2010), para obtenção de altas produtividades de trigo são essenciais o manejo adequado da adubação nitrogenada e a utilização de cultivares de alto potencial produtivo. O nitrogênio (N) é um elemento essencial para as plantas, pois participa de uma série de rotas metabólicas-chave em sua bioquímica, sendo constituinte de importantes biomoléculas, tais como ATP, NADH, NADPH, clorofila, proteínas de armazenamento, ácidos nucléicos e enzimas (HARPER, 1994).

No Estado de Goiás, a dose utilizada de nitrogênio é recomendada em função da cultura anterior e da expectativa de rendimento, no entanto, a resistência da planta ao acamamento também deve ser considerada. Doses menores de $\mathrm{N}$ limitam a produtividade, enquanto doses maiores podem levar ao acamamento de plantas, devido ao maior desenvolvimento vegetativo e aumento do comprimento dos entrenós, o que dificulta a colheita e reduz a produtividade (ZAGONEL et al. 2002).

Para minimizar a ocorrência do acamamento de plantas nestas situações têm-se avaliado o uso de reguladores de crescimento, como o etil-trinexapac (BERTI et al., 2007; ZAGONEL; FERNANDES, 2007). Os reguladores de crescimento têm sido empregados para tornar a arquitetura das plantas mais adaptada e eficiente quanto ao uso dos recursos naturais e dos insumos, a fim de suportar elevados rendimentos agronômicos (SOUZA et al., 2013). Em cereais de inverno, o princípio ativo etil-trinexapac vem sendo utilizado em lavouras comerciais no Brasil, e seu uso tem sido indicado para a redução do crescimento das plantas em altura e para o fortalecimento dos entrenós.

Estudos avaliando a adubação nitrogenada são fundamentais para atualizar as recomendações técnicas e disponibilizar tecnologias que proporcionem produções economicamente satisfatórias. Vários autores observaram respostas positivas, para o aumento da produtividade, utilizando doses de $\mathrm{N}$ de até $70,0 \mathrm{~kg} \mathrm{ha}^{-1}$ (ZAGONEL et al., 2002; TRINDADE et al., 2006; TEIXEIRA FILHO et al., 2007). No entanto, esta resposta pode ser alterada, em função da aplicação de reguladores de crescimento, cultivar utilizada e condições climáticas.

Desse modo, objetivou-se avaliar o efeito de doses de nitrogênio em cobertura e o efeito do regulador de crescimento etil-trinexapac no trigo, sobre as características produtivas do trigo (Triticum aestivum L.), cultivado em sistema de semeadura direta, em sucessão a cultura da soja.

\section{MATERIAL E MÉTODOS}

O trabalho foi conduzido no município de Jataí-GO, na área fazenda experimental da Universidade Federal de Goiás-Regional Jataí, localizado a 170 88' de Latitude Sul, 510 71' de Longitude Oeste a 662,8 metros de altitude. Segundo a classificação de Köppen o clima da região é classificado como $\mathrm{Aw}$, clima tropical com estação seca de inverno. Os dados referentes às temperaturas máxima, mínima e precipitação pluvial durante a condução do experimento, foram coletados na Estação Meteorológica de Observação de Superfície Automática localizada na Universidade Federal de Goiás-Regional Jataí, pertencente ao Instituto Nacional de Meteorologia (Figura 1). 
Figura 1. Precipitação pluvial (】), temperaturas média (-), registradas durante a condução do experimento, no ano de 2017. Jataí, GO.

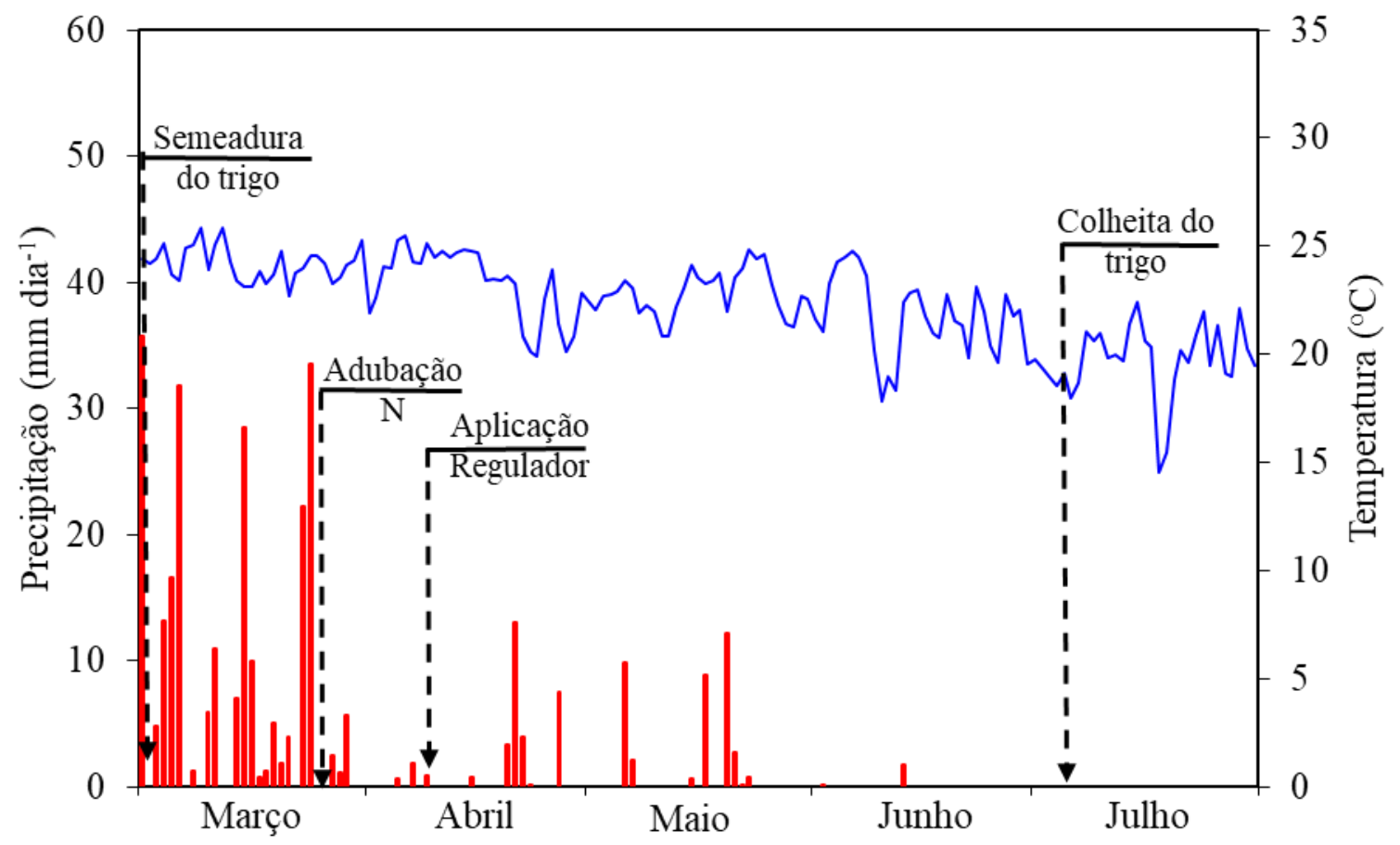

O solo da área é classificado como Latossolo Vermelho distroférrico (EMBRAPA, 2018) o qual se encontrava sob sistema de integração lavoura-pecuária. Antes da instalação do experimento foi realizada análise granulométrica apresentando teores de 680, 125 e $195 \mathrm{~g} \mathrm{~kg}^{-1}$ de argila, silte e areia, respectivamente, e os atributos químicos do solo, que estão apresentados na Tabela 1.

Tabela 1. Valores dos atributos químicos atribuídos ao solo no início da implantação do experimento, coleta na camada de $0-20 \mathrm{~cm}$. Jataí-GO 2016.

\begin{tabular}{|c|c|c|c|c|c|c|c|c|}
\hline $\mathrm{pH}$ & K & $\mathrm{P}(\mathrm{mel})$ & $\mathrm{Ca}$ & $\mathrm{Mg}$ & $\mathrm{Al}$ & $\mathrm{H}+\mathrm{Al}$ & CTC & $\mathrm{V}$ \\
\hline$-\mathrm{CaCl}_{2-}$ & \multicolumn{2}{|c|}{----mg dm ${ }^{-3}----$} & \multicolumn{5}{|c|}{ 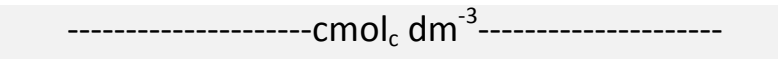 } & $\%$ \\
\hline 5,2 & 119 & 8,8 & 2,81 & 1,07 & 0,08 & 5,6 & 9,8 & 42,7 \\
\hline$S$ & B & $\mathrm{Cu}$ & $\mathrm{Fe}$ & & $\mathrm{Mn}$ & $\mathrm{Zn}$ & & $\mathrm{Na}$ \\
\hline ------ & ---- & 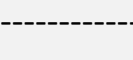 & --------- & $g \mathrm{dm}$ & $\ldots$ & 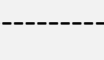 & & ----- \\
\hline 7,9 & 0,11 & 8,1 & 34 & & 40,2 & 3,5 & & 1,8 \\
\hline
\end{tabular}

O experimento possuiu o delineamento experimental em blocos casualizados em esquema fatorial $5 \times 2$, com 4 repetições. Os tratamentos foram compostos por cinco doses de nitrogênio aplicado em cobertura $(0,20,40,80$ e $160 \mathrm{~kg} \mathrm{ha}^{-1}$ de $\mathrm{N}$ ) e duas doses do regulador vegetal etil-trinexapac (0 e $100 \mathrm{~g} \mathrm{ha}^{-1}$ do ingrediente ativo) na cultura do trigo.

Antes da implantação do experimento, no dia 23 de fevereiro de 2017, foi realizada dessecação da cobertura vegetal da área mediante a aplicação de herbicida glifosato
(2.160 $\mathrm{g} \mathrm{ha}^{-1}$ de i.a.), utilizando um volume de $150 \mathrm{~L} \mathrm{ha}^{-1}$. No dia 1 de março de 2017 foi realizada a semeadura, no espaçamento de 0,17 $\mathrm{m}$ e densidade de semeadura de 300 sementes $\mathrm{m}^{2}$. As sementes foram previamente tratadas 50 $\mathrm{g}$ de thiamethoxam $+60 \mathrm{~g}$ de carboxina e $+60 \mathrm{~g}$ tiram por $100 \mathrm{~kg}$ de sementes. A adubação de base foi realizada no sulco de semeadura utilizando-se $300 \mathrm{~kg} \mathrm{ha}^{-1}$ formulado 05-25-25 de $\mathrm{N}-\mathrm{P}_{2} \mathrm{O}_{5}-\mathrm{K}_{2} \mathrm{O}$, que corresponde a $15 \mathrm{~kg} \mathrm{ha}^{-1}$ de $\mathrm{N}$, $75 \mathrm{~kg} \mathrm{ha}^{-1}$ de $\mathrm{P}_{2} \mathrm{O}_{5}$ e $75 \mathrm{~kg} \mathrm{ha}^{-1}$ de $\mathrm{K}_{2} \mathrm{O}$. 
A adubação nitrogenada de cobertura foi realizada no início do perfilhamento da cultura, no dia 25 de março de 2017, utilizando as doses de $0,20,40,80$ e $160 \mathrm{~kg} \mathrm{ha}^{-1}$ e como fonte a ureia (45\% de N). A aplicação do regulador vegetal ethil-trinexapac ocorreu quando o primeiro e segundo nó visíveis, no dia 13 de abril de 2017, nas doses de 0 e $100 \mathrm{~g} \mathrm{ha}^{-1}$ do ingrediente ativo. A área foi monitorada semanalmente, e o manejo fitossanitário realizado de acordo com as necessidades da cultura.

Para as avaliações foram consideradas as linhas centrais desprezando $1 \mathrm{~m}$ na extremidade de cada fileira de plantas e uma fileira de cada lado da unidade experimental. A massa da matéria seca foi determinada no início do florescimento da cultura, onde foram coletadas plantas contidas em $1 \mathrm{~m}$, que foram acondicionadas em saco de papel e levadas para secagem em estufa de ventilação forçada a temperatura média de $60-75{ }^{\circ} \mathrm{C}$, até atingir massa constante e posterior pesagem, transformando os dados para $\mathrm{kg} \mathrm{ha}^{-1}$.

Foram analisados os componentes morfológicos quando as plantas encontravam-se no estágio de grãos em estado duro, coletandose 15 plantas ao acaso, na área útil de cada unidade experimental: a) Altura de planta $(\mathrm{cm})-$ determinada pela distância média compreendida entre o nível do solo e a extremidade superior da espiga mais alta; b) Altura da folha bandeira $(\mathrm{cm})$ - determinada pela distância média compreendida entre o nível do solo e a inserção da folha bandeira; c) Altura de inserção da espiga $(\mathrm{cm})$ - determinada pela distância média compreendida entre o nível do solo e a inserção da espiga terminal; d) Comprimento da espiga $(\mathrm{cm})$ - determinada pela distância média compreendida entre a base e a extremidade superior da espiga; e) Distância fonte e dreno $(\mathrm{cm})$ - determinada pela distância média compreendida entre a inserção da folha bandeira e inserção da espiga; f) Número de espigas por metro quadrado - determinado pela contagem do número de espigas contidas em $4,0 \mathrm{~m}$ de fileira de cada unidade experimental e calculado por metro quadrado, no momento da colheita.

Quanto aos componentes de produção do trigo, avaliados no momento anterior a colheita foram, onde foram colhidas 15 espigas de trigo ao acaso da área útil de cada subparcela, acondicionadas em sacos de papel, identificadas e levadas ao laboratório, para as seguintes determinações: a) Número de espiguetas por espiga - determinado a partir da contagem de todas as espiguetas com grãos da espiga; b) Número de grãos por espiga - obtido a partir da divisão do número de grãos pelo número de espigas, de cada unidade experimental; c) Número de grãos por espigueta - determinado a partir da divisão do número de grãos por espiga pelo número de espiguetas por espiga, de cada unidade experimental; d) Fertilidade das espiguetas - determinada a partir da relação: número de espiguetas granadas por espiga pelo número total de espiguetas por espiga x 100; e) Massa de 1.000 grãos (g) - foi determinado através da coleta ao acaso e pesagem de quatro amostras de 1.000 grãos de cada unidade experimental, seguida por pesagens com transformação dos resultados a $13 \%$ de umidade em base úmida (Umidade determinada por NIR reflectância no infravermelho próximo); f) Massa hectolítrica (kg) - correspondente à massa de grãos ocupada em um volume de 100 L, determinada em balança digital, com teor de água dos grãos corrigidos para $13 \%$ (Umidade determinada por NIR - reflectância no infravermelho próximo); g) Proteína nos grãos (\%) - foi determinada por reflectância no infravermelho próximo; h) Produtividade de grãos $\left(\mathrm{kg} \mathrm{ha}^{-1}\right)$ - foi determinada mediante a colheita mecanizada (colhedora de parcelas) de 8 fileiras de plantas de $4 \mathrm{~m}$ de comprimento em cada unidade experimental, com transformação dos resultados a $13 \%$ de umidade (Umidade determinada por NIR - reflectância no infravermelho próximo).

Análise estatística

Os dados foram submetidos a análise de variância e as médias do fator doses do regulador de crescimento comparadas pelo teste DMS a $5 \%$ de probabilidade, e as médias do fator doses de nitrogênio foram ajustadas a funções matemáticas a $5 \%$ de probabilidade, utilizando o programa Sisvar 4.2 (FERREIRA, 2008).

\section{RESULTADOS E DISCUSSÕES}

Na Tabela 3 estão contidos os resultados de altura de planta, altura da folha bandeira, altura de inserção da espiga, distância fonte e dreno e comprimento de espiga em função da aplicação de regulador de crescimento e doses de nitrogênio. 
Tabela 3. Altura de planta, altura da folha bandeira, altura de inserção da espiga, distância fonte e dreno e comprimento de espiga em função da aplicação de regulador de crescimento e doses de nitrogênio. A probabilidade de F também está apresentada. Jataí, GO.

\begin{tabular}{lccccc}
\hline Tratamentos & $\begin{array}{c}\text { Altura } \\
\text { de planta }\end{array}$ & $\begin{array}{c}\text { Altura da } \\
\text { folha bandeira }\end{array}$ & $\begin{array}{c}\text { Altura de inserção } \\
\text { da espiga }\end{array}$ & $\begin{array}{c}\text { Distância fonte- } \\
\text { dreno }\end{array}$ & $\begin{array}{c}\text { Comprimento } \\
\text { de espiga }\end{array}$ \\
\hline $\begin{array}{l}\text { Regulador } \\
\text { Controle }\end{array}$ & 52,0 a* & $37,9 \mathrm{a}$ & $45,9 \mathrm{a}$ & $7,9 \mathrm{a}$ & $6,1 \mathrm{a}$ \\
$\begin{array}{l}\text { Trinexapaque-etílico } \\
\text { Nitrogênio (kg ha }{ }^{-1} \text { ) }\end{array}$ & $42,8 \mathrm{~b}$ & $32,9 \mathrm{~b}$ & $36,8 \mathrm{~b}$ & $3,8 \mathrm{~b}$ & $6,0 \mathrm{a}$ \\
\hline 0 & & & & & \\
20 & 49,2 & 36,6 & 43,8 & 7,1 & 5,4 \\
40 & 46,2 & 34,5 & 39,9 & 5,3 & 6,3 \\
80 & 45,8 & 34,7 & 39,9 & 5,1 & 5,9 \\
160 & 47,3 & 35,0 & 40,9 & 5,9 & 6,4 \\
\hline Probabilidade de F & 48,6 & 36,4 & 42,4 & 5,9 & 6,2 \\
Bloco & & & & & \\
Regulador (R) & 0,0017 & 0,0047 & 0,0028 & 0,0277 & 0,0599 \\
Nitrogênio (N) & $<0,0001$ & $<0,0001$ & $<0,0001$ & $<0,0001$ & 0,8073 \\
R x N & 0,3234 & 0,4521 & 0,1599 & 0,1396 & 0,3357 \\
\hline C.V. (\%) & 0,8837 & 0,9692 & 0,9283 & 0,4869 & 0,3643 \\
\hline
\end{tabular}

*Médias seguidas pela mesma letra não diferem entre si $(p>0,05)$ pelo teste DMS.

Com a aplicação do regulador (Trinexapaque-etílico), todas as variáveis biométricas foram reduzidas, como a altura da planta, altura da folha bandeira, altura da inserção da espiga, a distância entre fonte e dreno, exceto para o comprimento da espiga que não foi alterado (Tabela 3). A redução da altura de plantas também foi observada por Berti el al. (2007), Espindula et al. (2010) e Fiorezi e Rodrigues (2014). Este efeito é típico do Trinexapaque-etílico, um inibidor de crescimento que atua no alongamento dos entrenós, ocasionando encurtamento do colmo e engrossamento da base do colmo, o que é extremamente desejável em sistemas de manejo com intensivo uso de insumos, em ambientes que estimulam o acamamento e quando é utilizado cultivares com tendência ao acamamento (PIRES et al., 2004).

Pode-se ressaltar que, o prolongamento do efeito da inibição da biossíntese de giberelina provocado pela aplicação do inibidor de crescimento na fase de alongamento dos primeiros entrenós da planta, interfere de forma significativa no desenvolvimento do último entrenó das plantas e da folha bandeira (Tabela 3). O transporte de açúcares pelo floema pode ocorrer entre órgãos distantes, mas normalmente um dreno é suprido de fotoassimilados pelas fontes próximas e, as relações fonte/dreno da planta, são continuamente modificadas com o desenvolvimento vegetal (PIMENTEL, 1998). Assim, considera-se que 0 transporte de carboidratos entre a fonte e o dreno envolve uma série de processos metabólicos ativos e passivos, e o encurtamento da distância entre a folha e a espiga em plantas de trigo pode resultar em aumento da taxa de translocação de assimilados, com reflexos significativos na produtividade de grãos (FIOREZI; RODRIGUES, 2014).

Contudo, não foi verificada interação significativa, bem como o efeito da adubação nitrogenada para nenhum dos parâmetros biométricos avaliados (Tabela 3). Uma das possíveis explicações para a ausência de efeito na altura de planta, altura da folha bandeira, altura da inserção da espiga, distância entre fonte e dreno com a utilização do nitrogênio é em função da área ter sido cultivada anteriormente com a cultura da soja, extremamente eficiente em fixar nitrogênio atmosférico incrementando os teores no solo, que segundo Wietholter (1996) pode contribuir com 17 a $59 \mathrm{~kg} \mathrm{ha}^{-1}$ de N. Outro fator a ser considerado é a baixa precipitação pluviométrica logo após a aplicação do $\mathrm{N}$ fertilizante (Figura 1), que pode ter reduzido a eficiência de aproveitamento do $\mathrm{N}$-fertilizante, que pode ter redistribuído o $\mathrm{N}$ absorvido para outras funções vitais da planta, como a sobrevivência de afilhos (PIRES et al., 2011).

De acordo com a Tabela 4, a massa de matéria seca, a fertilidade das espiguetas, o 
número de grãos por espiga, o número de grãos por espigueta e a massa de 1000 grãos não foram afetadas por nenhum dos fatores avaliados, bem como não houve interação entre os fatores.

Nos tratamentos que receberam $\mathrm{N}$ os componentes produtivos não foram alterados (Tabela 4), sendo reflexo dos resultados observados nos componentes biométricos das plantas de trigo (Tabela 3). Contudo, o número de espigas por $\mathrm{m}^{2}$ aumentou com a adubação nitrogenada até a dose estimada de $52 \mathrm{~kg} \mathrm{ha}^{-1}$ de nitrogênio, o que proporcionou um número de
282 espigas por $\mathrm{m}^{2}$ (Figura 2). Esse resultado reforça a hipótese de que o $\mathrm{N}$-absorvido pelas plantas foram destinados para emissão e sobrevivência dos afilhos em detrimento de seu crescimento. Pagliosa et al. (2013) também observaram resultados semelhantes, contudo o maior número de afilhos foi obtido na dose de $120 \mathrm{~kg} \mathrm{ha}^{-1} \mathrm{~N}$, muito superior à do presente estudo, mas que é justificada em razão das condições edafoclimáticas mais favoráveis para o desenvolvimento do trigo em Pato Branco (PR).

Tabela 4. Massa de matéria seca, número de espigas por $\mathrm{m}^{2}$, fertilidade das espiguetas, número de grãos por espiga, número de grãos por espigueta e massa de mil grãos em função da aplicação de regulador de crescimento e doses de nitrogênio. A probabilidade de $\mathrm{F}$ também está apresentada. Jataí, GO.

\begin{tabular}{|c|c|c|c|c|c|c|}
\hline Tratamentos & $\begin{array}{l}\text { Massa } \\
\text { seca }\end{array}$ & $\begin{array}{l}\text { Espigas } \\
\text { por } \mathrm{m}^{2}\end{array}$ & $\begin{array}{l}\text { Fertilidade } \\
\text { das } \\
\text { espiguetas }\end{array}$ & $\begin{array}{l}\text { Grãos por } \\
\text { espiga }\end{array}$ & $\begin{array}{l}\text { Grãos por } \\
\text { espigueta }\end{array}$ & $\begin{array}{l}\text { Massa de } \\
1000 \text { grãos }\end{array}$ \\
\hline & $\mathrm{kg} \mathrm{ha}^{-1}$ & $\mathrm{n}^{\circ}$ & $\%$ & $\mathrm{n}^{\circ}$ & $\mathrm{n}^{\circ}$ & $\mathrm{g}$ \\
\hline \multicolumn{7}{|l|}{$\underline{\text { Regulador }}$} \\
\hline Controle & 3350 a* & 273 a & $96,5 \mathrm{a}$ & $21,9 \mathrm{a}$ & $2,1 \mathrm{a}$ & $22,57 \mathrm{a}$ \\
\hline $\begin{array}{l}\text { Trinexapaque-etílico } \\
\text { Nitrogênio }\left(\mathrm{kg} \mathrm{ha}^{-1}\right)\end{array}$ & $3357 a$ & 276 a & $96,7 \mathrm{a}$ & $25,2 \mathrm{a}$ & $2,0 \mathrm{a}$ & $22,52 \mathrm{a}$ \\
\hline 0 & 3297 & - & 97,5 & 25,7 & 2,1 & 22,45 \\
\hline 20 & 3374 & - & 96,5 & 25,7 & 2,1 & 22,60 \\
\hline 40 & 3497 & - & 97,3 & 24,1 & 1,9 & 22,92 \\
\hline 80 & 3244 & - & 96,3 & 25,1 & 2,0 & 22,65 \\
\hline 160 & 3356 & - & 95,5 & 24,6 & 2,1 & 22,10 \\
\hline \multicolumn{7}{|l|}{ Probabilidade de F } \\
\hline Bloco & 0,0036 & 0,4613 & 0,1183 & 0,2936 & 0,5711 & 0,8894 \\
\hline Regulador (R) & 0,9683 & 0,6171 & 0,7705 & 0,8235 & 0,4135 & 0,8618 \\
\hline Nitrogênio (N) & 0,9820 & 0,0381 & 0,3687 & 0,9582 & 0,9313 & 0,4757 \\
\hline $\mathrm{R} \times \mathrm{N}$ & 0,7401 & 0,8408 & 0,4201 & 0,6064 & 0,9399 & 0,7969 \\
\hline C.V. (\%) & 17,96 & 8,54 & 2,22 & 20,19 & 19,77 & 3,99 \\
\hline
\end{tabular}

*Médias seguidas pela mesma letra não diferem entre si $(p>0,05)$ pelo teste DMS. - dados apresentados na Figura 2.

Figura 2. Número de espigas por $m^{2}$ em função da aplicação de doses de nitrogênio em cobertura. Jataí, GO.

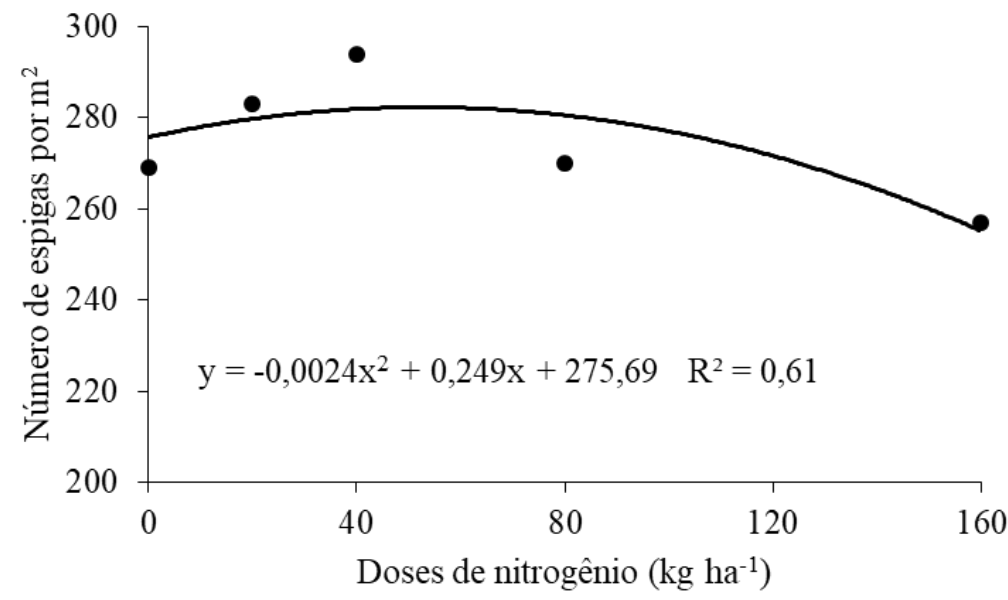


De acordo com a Tabela 5, o peso hectolitro e a proteína nos grãos não foram afetadas por nenhum dos fatores avaliados, bem como não houve interação entre os fatores. Esse efeito no peso hectolitro está relacionado com a não ocorrência de competição por fotoassimilados pelos órgãos da planta, o que prejudicaria o enchimento de grãos, sendo visível na massa de mil grãos (Tabela 4). O teor de proteína nos grãos é influenciado pela época de aplicação do $\mathrm{N}$, sendo que a época com maior probabilidade de incrementar a proteína é a aplicação no alongamento (ZEBARTH; SHEARD, 1992; BULMAN; SMITH, 1993), justificando os resultados obtidos, uma vez que, a adubação nitrogenada procedeu-se na fase de afilhamento da cultura do trigo.

Tabela 5. Peso hectolitro, proteína nos grãos e produtividade de grãos em função da aplicação de regulador de crescimento e doses de nitrogênio. A probabilidade de $\mathrm{F}$ também está apresentada. Jataí, GO.

\begin{tabular}{|c|c|c|c|}
\hline Tratamentos & $\begin{array}{l}\text { Peso hectolitro } \\
\mathrm{kg} \mathrm{hl}^{-1}\end{array}$ & $\begin{array}{c}\text { Proteína nos grãos } \\
\%\end{array}$ & $\begin{array}{l}\text { Produtividade de grãos } \\
\qquad \mathrm{kg} \mathrm{ha}^{-1}\end{array}$ \\
\hline \multicolumn{4}{|l|}{ Regulador } \\
\hline$\overline{\text { Controle }}$ & $75 \mathrm{a}^{*}$ & $18,2 \mathrm{a}$ & $1370 \mathrm{a}$ \\
\hline Trinexapaque-etílico & $75 a$ & $17,9 \mathrm{a}$ & $1300 \mathrm{a}$ \\
\hline \multicolumn{4}{|l|}{ Nitrogênio $\left(\mathrm{kg} \mathrm{ha}^{-1}\right)$} \\
\hline 0 & 75 & 17,7 & - \\
\hline 20 & 75 & 17,7 & - \\
\hline 40 & 75 & 17,9 & - \\
\hline 80 & 74 & 18,5 & - \\
\hline 160 & 75 & 18,4 & - \\
\hline \multicolumn{4}{|l|}{ Probabilidade de F } \\
\hline Bloco & 0,7697 & 0,0767 & 0,5953 \\
\hline Regulador (R) & 0,1016 & 0,2774 & 0,1319 \\
\hline Nitrogênio (N) & 0,2452 & 0,0677 & 0,0213 \\
\hline $\mathrm{R} \times \mathrm{N}$ & 0,5560 & 0,9143 & 0,1333 \\
\hline C.V. (\%) & 1,43 & 3,55 & 10,62 \\
\hline
\end{tabular}

*Médias seguidas pela mesma letra não diferem entre si $(p>0,05)$ pelo teste DMS. - dados apresentados na Figura 3.

Apenas a produtividade de grãos foi afetada pelo nitrogênio, com ajuste quadrático, e maior produtividade de grãos obtida com a dose estimada de $59 \mathrm{~kg} \mathrm{ha}^{-1}$ de $\mathrm{N}$, alcançando produtividade de $1397 \mathrm{~kg} \mathrm{ha}^{-1}$ (Figura 3). Estes resultados são reflexo do maior número de espigas por $\mathrm{m}^{2}$ (Tabela 4), que apresentam elevada correlação positiva $(r=0,96 ; P<0,01)$. Resultados semelhantes foram observados por Wendling et al. (2007) que constataram resposta quadrática à aplicação de $\mathrm{N}$ para trigo cultivado após soja.

Contudo, é importante destacar que na dose de $59 \mathrm{~kg} \mathrm{ha}^{-1}$ de $\mathrm{N}$ o incremento de $69 \mathrm{~kg} \mathrm{ha}^{-}$ ${ }^{1}$ na produtividade de grãos de trigo em relação a dose $0 \mathrm{~kg} \mathrm{ha}^{-1}$ de $\mathrm{N}$ não traria retorno econômico, visto que o custo da aplicação do fertilizante seria maior em relação ao valor dos grãos de trigo. Fica evidente que, em ambientes com condições ambientais mais restritivas, como altas temperaturas e baixa disponibilidade hídrica no final do ciclo da cultura do trigo, e em sucessão a soja justifica a redução da adubação nitrogenada.

Com relação a baixa produtividade de grãos observada, independentemente dos fatores estudados, esta pode ser atribuída a baixa precipitação pluvial durante o enchimento dos grãos e a alta incidência de brusone, doença que afeta diretamente as espigas do trigo. 
Figura 3. Produtividade de grãos em função da aplicação de doses de nitrogênio em cobertura. Jataí, GO.

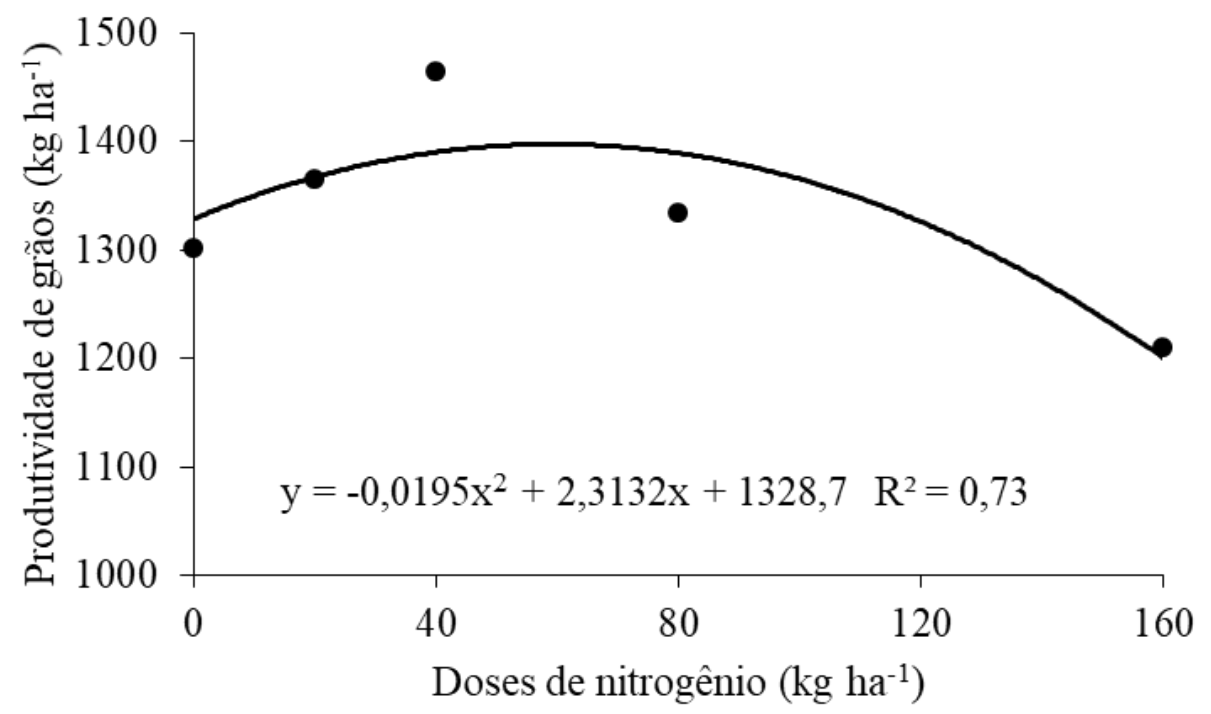

Cabe destacar que, apesar da aplicação do regulador de crescimento não ter alterado nenhum dos componentes produtivos e a produtividade de grãos, é possível que as alterações morfológicas nas plantas de trigo possam resultar em efeitos significativos, em termos de produtividade, para materiais genéticos que apresentem maior propensão ao acamamento ou mesmo condições hídricas ambientais específicas, como em condições irrigadas.

\section{CONCLUSÃO}

O regulador de crescimento altera os componentes morfológicos do trigo, porém não altera os componentes produtivos e a produtividade de grãos, não justificando seu uso nas condições em que ocorreu o estudo.

A adubação nitrogenada não altera os componentes morfológicos das plantas do trigo, mas aumenta o número de espigas por $\mathrm{m}^{2}$ (afilhos) até dose de $52 \mathrm{~kg} \mathrm{ha}^{-1}$ de $\mathrm{N}$, refletindo no aumento da produtividade até a dose de $59 \mathrm{~kg}$ $\mathrm{ha}^{-1}$.

\section{REFERÊNCIAS}

BERTI, M.; ZAGONEL, J.; FERNANDES, E. C. Produtividade de cultivares de trigo em função do trinexapacethyl e doses de nitrogênio. Scientia Agraria, v.8, p.127-134, 2007. https://doi.org/10.5380/rsa.v8i2.8376

BULMAN, P.; SMITH, D.L. Grain protein response of spring barley to high rates and post-anthesis application of fertilizer nitrogen. Agronomy
Journal, Madison, v.85, n.6, p.1109-1113, 1993. https://doi.org/10.2134/agronj1993.0002196200 $\underline{8500060003 x}$

CONAB. Acompanhamento da safra brasileira: grãos 2016/2017, sétimo levantamento - Abril 2017. Brasília, 2017.

EMBRAPA. Sistema brasileiro de classificação de solos. 5. ed. Brasília: Embrapa Tecnologia da Informação, 2018. E-book.

ESPINDULA, M.C.; ROCHA, V.S.; SOUZA, L.T.; SOUZA, M.A.; GROSSI, J.A.S. Efeito de reguladores de crescimento na elongação do colmo de trigo. Acta Scientiarum Agronomy, Maringá, v.32, n.1, p. 109-116, 2010. https://doi.org/10.4025/actasciagron.v32i1.943

FERREIRA, D. F. SISVAR: a program for statistical analysis and teaching. Revista Symposium, v.6, p.36-41, 2008.

FIOREZI, S.L.; RODRIGUES, J.D. Componentes produtivos do trigo afetados pela densidade de semeadura e aplicação de regulador. Semina: Ciências Agrárias, Londrina, v.35, n.1, p.39-54, $2014 . \quad$ https://doi.org/10.5433/1679$\underline{0359.2014 v 35 n 1 p 39}$

HARPER, J.E. Nitrogen metabolism. In: BOOTE, K.J. et. al. Physiology and determination of crop yield. American Society of Agronomy, 1994. Cap.11, p.285-302. 
PAGLIOSA, E.E.; BENIN, G.; BIEZUS, E.; BECHE, E.; SILVA, C.L.; MARCHESE, J.A.; MARTIN, T.N. Trinexapac-ethyl e adubação nitrogenada na cultura do trigo. Planta Daninha, v.31, n.3, p. 623-630, 2013. https://doi.org/10.1590/S010083582013000300014

PIMENTEL, C. Metabolismo do carbono na agricultura tropical. Seropédica: EDUR, 1998. $150 p$.

PIRES, J.L.F.; VARGAS, L.; CUNHA, G.R. Trigo no Brasil: Bases para produção competitiva e sustentável. Passo Fundo: Embrapa Trigo, 2011. $488 p$.

PIRES, J. L. F. et al. Avaliação de cultivares de trigo em sistema de manejo tradicional e otimizado. Passo Fundo: Embrapa Trigo, 2004. $19 p$.

SOUZA, C.A.; FIGUEIREDO, B.P.; COELHO, C.M.M.; CASA, R.C.; SANGOI, L. Arquitetura de plantas e produtividade da soja decorrente do uso de redutores de crescimento. Bioscience Journal, v.29, p.634-643, 2013.

TEIXEIRA FILHO, M.C.M.; BUZETTI, S.; ANDREOTTI, M.; ARF, O.; BENETT, C.G.S. Doses, fontes e épocas de aplicação de nitrogênio em trigo irrigado em plantio direto. Pesquisa Agropecuária Brasileira, v. 45, n. 8, p. 797-804, $2010 . \quad$ https://doi.org/10.1590/S0100$\underline{204 \times 2010000800004}$

TRINDADE, M.G.; STONE, L.F.; HEINEMANN, A.B.; CÁNOVAS, A.D.; MOREIRA, J.A.A. Nitrogênio e água como fatores de produtividade do trigo no Cerrado. Revista Brasileira de Engenharia Agrícola e Ambiental, v.10, p.24-29, 2006. https://doi.org/10.1590/S1415-

$\underline{43662006000100004}$

WENDLING, A.; ELTZ, F.L.F.; CUBILLA, M.M.; AMADO, J.C.; MIELNICZUK, J.; LOVATO, T. Recomendação de adubação nitrogenada para trigo em sucessão ao milho e soja sob sistema plantio direto no Paraguai. Revista Brasileira de Ciência do Solo, v.31, p. 985-994, 2007. https://doi.org/10.1590/S0100$\underline{06832007000500015}$
WIETHÖLTER, S. Adubação nitrogenada no sistema plantio direto. Passo Fundo: EmbrapaCNPT, 1996. 44p

ZAGONEL, J.; FERNANDES, E. C. Doses e épocas de aplicação de redutor de crescimento afetando cultivares de trigo em duas doses de nitrogênio. Planta Daninha, v. 25, n. 2, p. 331$339, \quad 2007 . \quad$ https://doi.org/10.1590/S0100$\underline{83582007000200013}$

ZAGONEL, J.; VENANCIO, W. S.; KUNZ, R. P.; TANAMATI, $H$. Doses de nitrogênio e densidade de plantas com e sem um regulador de crescimento afetando o trigo, cultivar OR1. Ciência Rural, Santa Maria, v.23, n.1, p. 25-29, 2002b. https://doi.org/10.1590/S010384782002000100005

ZEBARTH, B.J.; SHEARD, R.W. Influence of rate and timing of nitrogen fertilization on yield and quality of hard red winter wheat in Ontario. Canadian Journal of Plant Science, Ottawa, v.72, n.1 p.13-19, 1992. https://doi.org/10.4141/cjps92-002

Recebido para publicação em 21/06/2018

Revisado em 06/01/2019

Aceito em 07/01/2019 